\title{
A novel approach for environmental evaluation of landfill mining
}

\author{
Per Frändegård, Joakim Krook, Niclas Svensson and Mats Eklund
}

\section{Linköping University Post Print}

\section{Tweet}

N.B.: When citing this work, cite the original article.

Original Publication:

Per Frändegård, Joakim Krook, Niclas Svensson and Mats Eklund, A novel approach for environmental evaluation of landfill mining, 2013, Journal of Cleaner Production, (55), 24-34. http://dx.doi.org/10.1016/j.jclepro.2012.05.045

Copyright: Elsevier

http://www.elsevier.com/

Postprint available at: Linköping University Electronic Press

http://urn.kb.se/resolve?urn=urn:nbn:se:liu:diva-86054 


\title{
A novel approach for environmental evaluation of landfill mining
}

\author{
Per Frändegård*, Joakim Krook, Niclas Svensson and Mats Eklund \\ Department of Management and Engineering, Environmental Technology and Management, \\ Linköping University, SE-581 83 Linköping, Sweden, *per.frandegard@liu.se,+4613285674
}

\begin{abstract}
Studies concerning landfill mining have historically focused on reclamation of land space and landfill remediation. A limited number of studies, however, have evaluated landfill mining combined with resource recovery, most of them being pilot studies or projects with little emphasis on resource extraction. This implies that many uncertainties remain related to landfill mining. With a growing interest in environmental concerns around the globe, the environmental evaluation of large-scale projects has become an increasingly important issue. A common way of conducting such an evaluation is to use Life Cycle Assessment (LCA). However, LCA by itself might not take into account all the inherent uncertainties in landfill mining. This article describes an approach for environmental evaluation of landfill mining that combines the principles of Life Cycle Assessment and Monte Carlo Simulation. In order to demonstrate its usability for planning and evaluation purposes, the approach is also applied to a hypothetical landfill mining case by presenting examples of the types of results it can produce. Results from this approach are presented as cumulative probability distributions, rather than a single result figure. By presenting results in this way, the landfill mining practitioner will get a more complete view of the processes involved and will have a better decision base.
\end{abstract}

\section{Keywords}

Life Cycle Assessment, landfill mining, remediation, resource recovery, environmental assessment, Monte Carlo Simulation

\section{Introduction}

Landfilling is the most common method for waste disposal globally (Eurostat, 2009; Kollikkathara et al., 2009). From an environmental perspective such disposal is inherently problematic since refined natural resources, in which both energy and materials have been invested, are wasted. Landfills are also well-known sources for various pollution problems such as long-term methane emissions and leaching of hazardous substances (cf. Mor et al., 2006; Sormunen et al., 2008; Flyhammar, 1997). However, these waste deposits could also be regarded as potential resource reservoirs. According to Kapur and Graedel (2006), for instance, about 300 million tonnes of copper is currently located in landfills and other waste repositories around the world (e.g. tailings and slag heaps), corresponding to more than 30 percent of the remaining reserves in known ores. Furthermore, landfills typically contain significant amounts of combustibles and earth construction materials (Cobb and Ruckstuhl, 1988; Obermeier et al., 1997; Hogland et al., 2004; Kurian et al., 2007).

In the context of ever-growing waste generation, landfill mining has been suggested as a potential concept to deal with these issues (Dickinson, 1995; Hogland, 2002). Landfill mining refers to the extraction, processing, treatment and/or recovery of deposited materials, and has been around as a concept for almost sixty years, starting in Israel in 1953 (Savage et al., 1993). This, however, was the only reported project for several decades, but in the 1990s interest in landfill mining started to grow. 
More than fifty projects have been carried out since then, the majority of which have focused on solving local concerns such as conservation of landfill space, remediation or other traditional waste management issues (Spencer, 1990; Dickinson, 1995; Cha et al., 1997; EPA, 1997; Van der Zee et al., 2004). Only a handful of these landfill mining initiatives have emphasized resource recovery and even fewer have used an integrated approach, i.e., to solve a local issue and at the same time extract recyclable materials from the landfill (Rettenberger, 1995; Hino et al., 1998; Zanetti and Godio, 2006). Since only a few projects with resource recovery have been carried out, the uncertainties relating to such an approach are great and the potential thus largely unclear.

For an actor, such as a commercial recycling company or a municipality, deciding whether to carry out a landfill mining project, there are several levels of uncertainties that need to be considered. There are, for instance, uncertainties on a multi-project level; if several landfills are possible targets for landfill mining, an actor has to establish which of the landfills has the greatest potential. There are also a variety of uncertainties on the project level. Baas et al. (2010) list four main types of uncertainties related to landfill mining projects, none of which have yet been sufficiently addressed: waste composition of landfills, efficiency of materials processing technologies, markets for materials recovered from landfills and environmental and health risks from excavating landfills. Hence, an actor needs to think about questions such as: What is the quantity of recyclable and hazardous materials in the landfill? How much of these materials can be separated out and at what quality level? How could this project be made conceivable from an economic and environmental perspective, and what are the critical factors for success?

With a growing interest in environmental concerns around the globe, the environmental evaluation of large-scale projects has become an increasingly important issue. For instance, it is often necessary for an actor planning to conduct a landfill mining project to be able to demonstrate the environmental impacts in order to obtain permits from the government. A common way of conducting such an evaluation is to use an analytical measure called Life Cycle Assessment (LCA). Uncertainties are inherent when an LCA is performed. Since the results from the LCA are used in decision support, these uncertainties need to be presented to the decision maker in a clear and transparent manner (Hong et al., 2010; Lloyd and Ries, 2007). In the interpretation phase of the LCA, this is often done through uncertainty analysis and sensitivity analysis. A problem with this approach, however, is that these analyses are often presented separately, apart from the main results of the LCA. Therefore, the decision makers might not give them the full attention needed in order to form a robust and transparent decision base (Heijungs and Huijbregts, 2004). This is of course especially true if the case in question concerns a system about which we have scarce data and limited experience, such as landfill mining. In a comparative study, uncertainties may in fact lead to the result that no single scenario can be statistically proven to be best (Finnveden, 2000, Reap et al., 2008). However, providing the probability distribution of the result, for instance by using Monte Carlo Simulation when performing an LCA, can give some valuable directions to a decision maker and at least purport to give an honest representation of the results by taking all uncertainty parameters into account.

The aim of this article is to describe an approach for environmental evaluation of landfill mining through combining the principles of Life Cycle Assessment and Monte Carlo Simulation. In order to demonstrate its usability for planning and evaluation purposes, the approach is also applied to a hypothetical landfill mining case by presenting examples of the types of results it can produce. 


\section{Background and the hypothetical case}

Of all the municipal solid waste created today in Sweden, only about 1 percent ends up in landfills (The Swedish Waste Association, 2010). However, Sweden has more than four thousand landfills, most of them small, old and lacking appropriate pollution prevention technologies. In recent years, discussions about the need for remediation of these landfills have started, and projects for realizing this goal have been initiated. It is with this background in mind that a hypothetical case has been created.

The basic outline for the hypothetical case is a Swedish municipal solid waste landfill which contains approximately one million tonnes of waste and is located in a rural area outside an average-sized Swedish city. In order to meet legal requirements regarding landfills, the owner of the landfill, i.e., the municipality, has decided that remediation is necessary. In order to characterize the composition of the landfill, waste samples of approximately 100 tonnes in total from different locations around the landfill have been collected and analyzed (cf. Kurian et al., 2003 and Quaghbeur et al., 2010). The different materials found were aggregated into ten deposited material types. For each type, the mean value (in weight percent) and the absolute value for the standard deviation were calculated, as shown in Table 1.

Table 1. The material composition (in weight \%) of the hypothetical landfill, presented as mean values and absolute standard deviations.

\begin{tabular}{|lrr|}
\hline Material type & Mean value & Std. dev. (abs) \\
\hline Soil & $56.3 \%$ & $14.2 \%$ \\
\hline Paper & $7.9 \%$ & $6.1 \%$ \\
\hline Plastic & $8.1 \%$ & $5.4 \%$ \\
\hline Wood & $7.4 \%$ & $4.3 \%$ \\
\hline Textiles & $3.3 \%$ & $1.3 \%$ \\
\hline Inert materials & $9.7 \%$ & $10.8 \%$ \\
\hline Organic waste & $2.7 \%$ & $2.0 \%$ \\
\hline Ferrous metals & $3.6 \%$ & $4.1 \%$ \\
\hline Non-ferrous metals & $0.8 \%$ & $4.1 \%$ \\
\hline Hazardous & $0.2 \%$ & $0.1 \%$ \\
\hline
\end{tabular}

The municipality is considering three potential scenarios for the remediation project, and would like these to be evaluated in order to be able to identify the most advantageous scenario from an environmental perspective. One simple option is to excavate the waste, rebuild and remediate the landfill and redeposit the waste, without any removal of materials from the landfill site. Another option is to use the concept of landfill mining, which here means to excavate the landfill, sort out the recyclable materials and then remediate and rebuild the landfill in order to safely dispose of the leftovers. This second option could be done in several different ways, but one of the main issues for the municipality is whether the project should use a mobile separation plant on-site at the landfill or transport the excavated material to a large-scale separation plant, which presumably has higher separation efficiencies. In order to develop the scenarios and obtain input to the project, several environmental experts were consulted.

\subsection{Scenario: Remediation only}

The scenario without any removal of material ("Remediation only") includes excavation of the waste, rebuilding the landfill according to Swedish landfill standards, and re-depositing the waste for final 
closure of the landfill. To rebuild and remediate the landfill, new waste deposit cells will have to be created, and systems for landfill gas collection and flaring put in place.

\subsection{Scenario: Mobile plant}

This scenario is characterized by simplicity; the plant should be transportable and separate out as much recyclable materials as possible with minimal time and set-up requirements. Together with environmental consultants, the municipality developed a feasible mobile plant consisting of four processes: star screen; air classifier; magnet; and an Eddy Current Separator (ECS) (Figure 1).

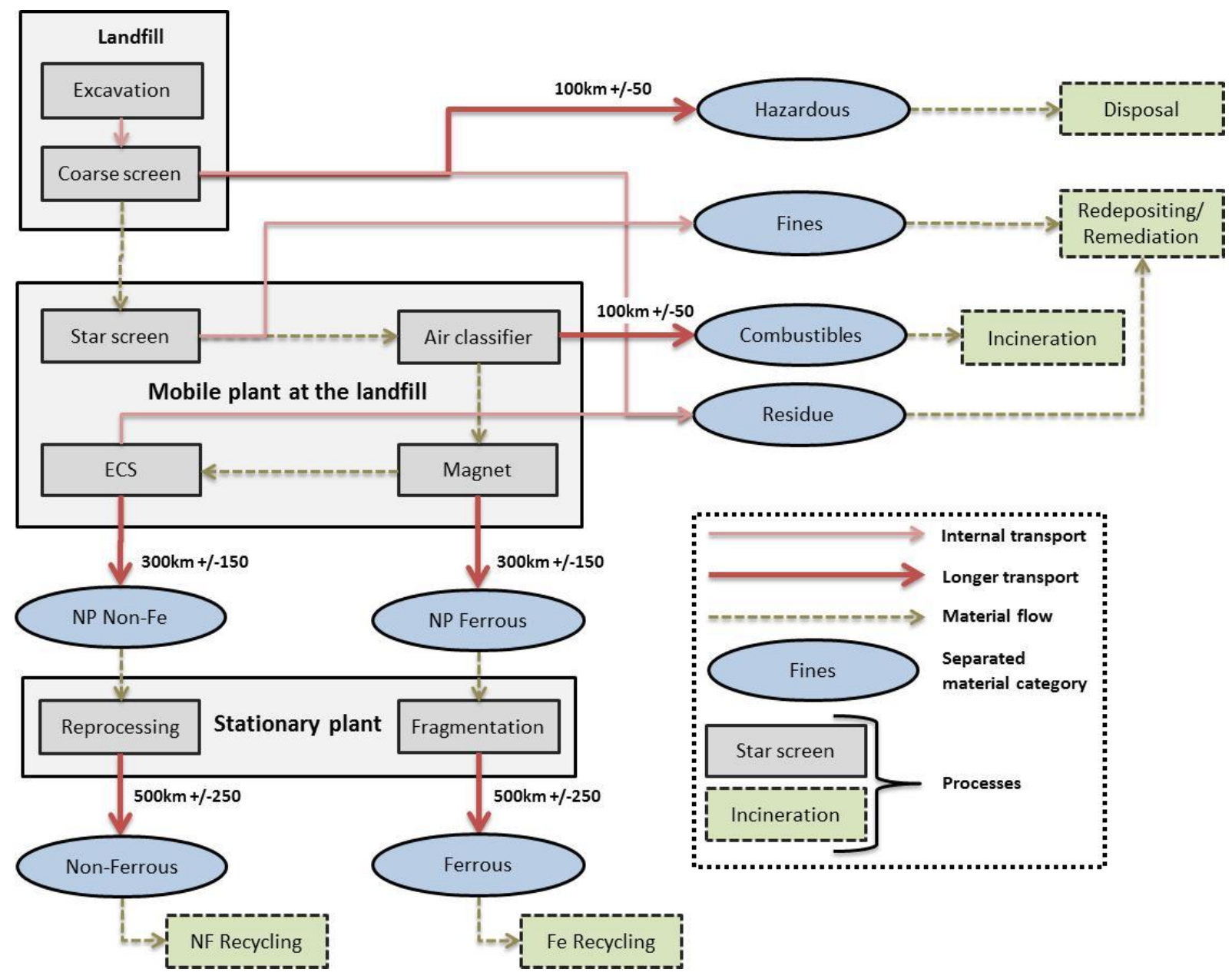

Figure 1. Overview of the mobile plant scenario showing processes, material flows and separated material categories. Estimated transport distances for the longer transports of recovered materials to recycling/treatment facilities are also shown in the figure, while internal transports are set to $10 \mathrm{~km}+/-5$. Non-processed non-ferrous and ferrous metals are denoted in the figure as NP Non-Fe and NP Ferrous, respectively.

In this suggested process, the deposited material is first excavated and dumped over a coarse screen, which separates out bulky hazardous products (e.g. refrigerators and oil barrels) and non-recyclable material. Next, the rest of the material enters the star screen, which separates out a material category for re-deposition called "fines", containing heavily degraded waste and cover material. Finally, the air classifier separates out combustibles such as paper, textiles and plastic, while the magnet and the ECS extract ferrous and non-ferrous metals, respectively. The environmental experts, however, also pointed out that the metals produced by the mobile plant are seldom clean enough for recycling; hence, prior to recycling these metals must be transported to a stationary metal processing plant for further refining. 


\subsection{Scenario: Stationary plant}

The plan behind this scenario was to make use of state-of-the-art technologies, with the emphasis on collecting as much material for recycling as technically possible. The environmental experts therefore designed a fairly sophisticated and ambitious option, which involves transporting approximately half of the excavated material to a stationary processing plant, Figure 2 . The stationary plant can be thought of as a combined ferrous and non-ferrous processing plant. At the landfill, the deposited material is first excavated and dumped through a coarse screen into a star screen, which is placed at the landfill in order to reduce the transport of soil from the landfill to the stationary plant. These mobile processes also collect bulky hazardous products (e.g. refrigerators and oil barrels) and residue material and a large share of the heavily degraded waste (fines). The hazardous material is transported from the landfill to a disposal facility. The rest of the material is then transported by truck to the stationary plant which separates five usable material categories: construction material; combustibles; non-ferrous; ferrous; and plastics. Four of these five usable material categories are transported by truck to different recycling plants, while the combustible material category is transported to the local waste incineration plant.

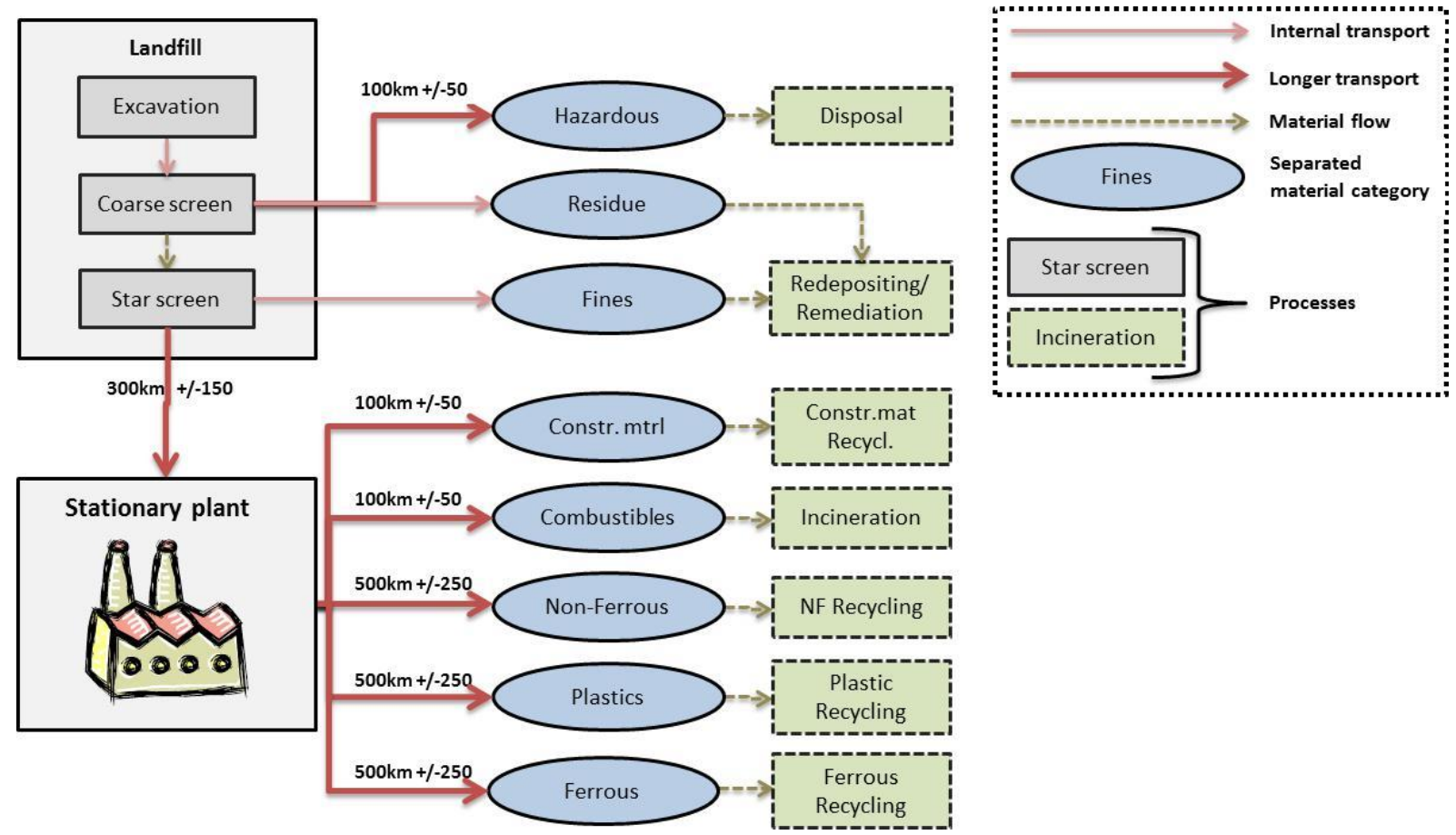

Figure 2. Overview of the stationary plant scenario showing processes, material flows and separated material categories. Estimated transport distances for the longer transports of recovered materials to recycling/treatment facilities are also shown in the figure, while internal transports are set to $10 \mathrm{~km}+/-5$.

\section{Presentation of the approach}

This study is based on life-cycle assessment methodologies in accordance with ISO 14040 (2006). The goal of the study is to evaluate the environmental impact of treatment of a certain mass of landfilled material, and to evaluate different concepts of treatment by using scenarios. The system function is to reduce environmental impacts and to realize potential resource recovery from landfills, and the functional unit is defined as the treatment of a certain mass of landfilled material. In order to address 
the uncertainties to which any actor considering a landfill mining project is exposed, an approach for evaluating environmental impacts from these types of projects was developed. Flexibility was emphasized, but the approach should still be powerful in the sense that it should manage a large number of uncertainty parameters, which it should also be possible to alter, add or remove dependent on case-specific conditions.

During the development, the international recycling company Stena Metall AB was consulted. This company organized an expert panel with the necessary understanding and experience regarding, for instance, separation technology efficiencies and the market and quality demands for secondary materials.

The interface, based on Excel, is divided into different sections depending on the type of input parameter, i.e., material composition of landfill, resource use of processes, efficiency of energy and material recovery, net emissions and life-cycle impact assessment, as seen in Figure 3. The approach simulates results using the Monte Carlo Simulation, which necessitates that every input parameter have a set mean value, a standard deviation, and an appropriate distribution, e.g. log-normal, triangular or rectangular. For a more in-depth description of the Monte Carlo method, see for instance Metropolis and Ulam (1949) or Kalos and Whitlock (2008).

Every aspect of the approach is based on scenarios, which can be created and set up individually, depending on the purpose and plan for realization of landfill mining. Scenarios can be developed, for instance as in the hypothetical case, to evaluate the impacts of different separation technologies and aims (remediation only, simple separation technologies using a mobile plant or extracting as much recyclable material as possible using a large stationary plant). 


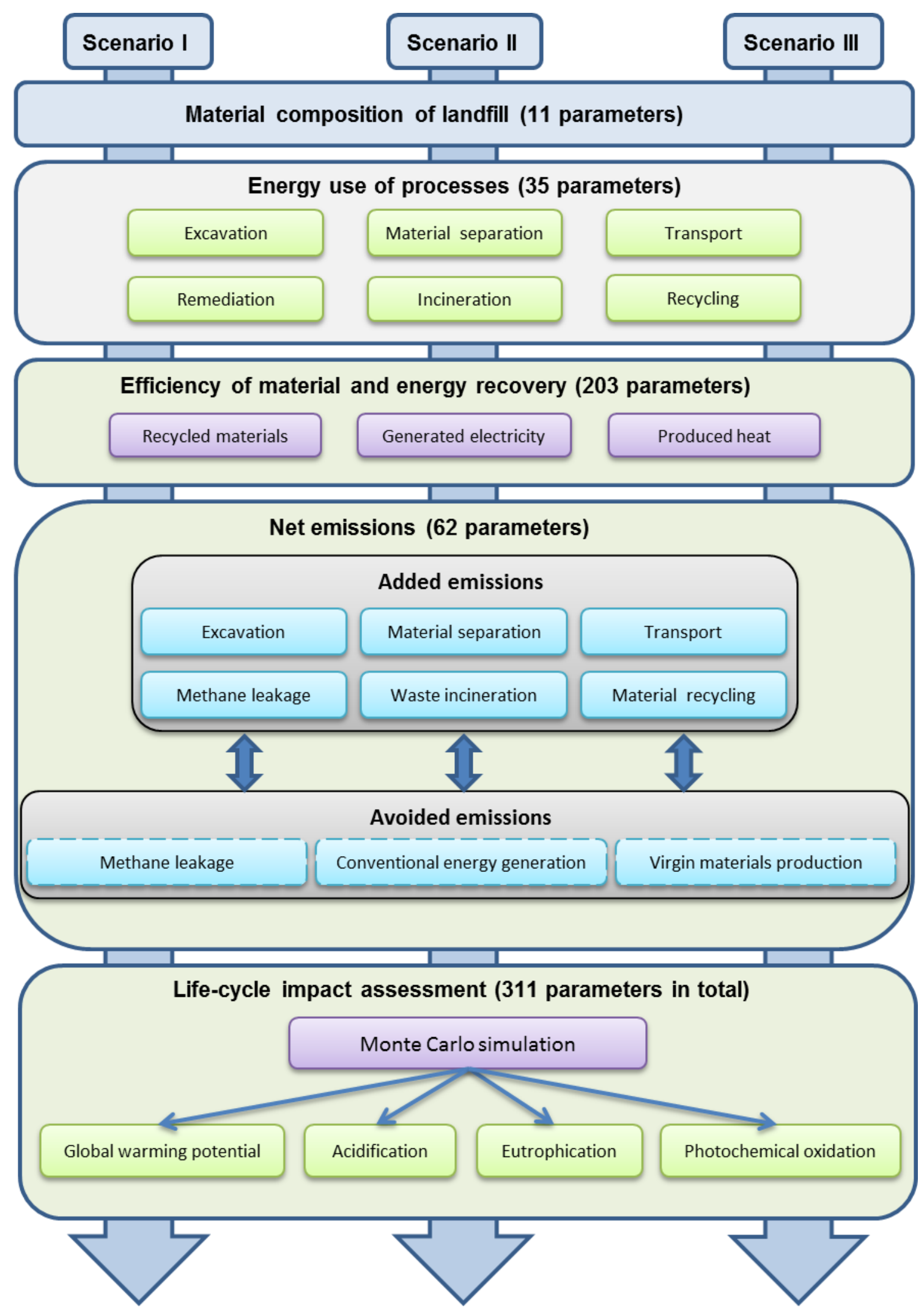

Figure 3. Illustration of the structure and data flow of the approach, divided into five sections. Each scenario in the model consists of a number of parameters connected to one of these sections. The number in parenthesis corresponds to the number of parameters in that section, with the exception of environmental assessment, which does not add any new parameters but instead uses every one of each scenario's parameters (311 in total) to produce the final results.

\subsection{Material composition of landfill}


The approach uses ten parameters as deposited material types: soil; paper; plastic; wood; textiles; inert materials; organic waste; ferrous metals; non-ferrous metals and hazardous, along with one parameter for the total amount of waste, i.e., eleven parameters in total for determining the material composition. Depending on the amount of data available for the specific case, a user can put in their own mean values, standard deviation, and distribution, or use the current default material composition. This default composition is based on a literature review of 16 landfill mining pilot studies from the industrialized part of the world (Cossu et al. (1995); Hogland et al. (1995); Hogland et al. (2004); Hull et al. (2005); Krogmann \& Qu (1997); Rettenberger (1995); Richard et al. (1996); Stessel \& Murphy (1991); Sormunen et al. (2008).

\subsection{Energy use of processes}

The scenarios consist of a number of processes, each using various energy sources. Hence, the energy use for each of these processes, along with their respective uncertainty distributions, needs to be included in the approach. Depending on how the scenarios are set up, different processes will obviously be included. For energy use by excavation, incineration, recycling, transport and remediation processes in the hypothetical case, generic data was acquired from the LCA database Ecoinvent (Frischknecht \& Rebitzer, 2005). Specific data for the energy use of the material separation processes was gathered from the recycling company Stena Metall AB. This included diesel usage for the separation processes included in the mobile plant and the electricity needed to run the large separation plant. In total, energy use of processes is described by 35 different input parameters.

\subsection{Efficiency of material and energy recovery}

To establish the separation efficiencies for the stationary plant and the mobile plant scenarios applied in the hypothetical case, the expert panel from Stena Metall AB was consulted. This company has vast experience in the field and has conducted its own pilot studies concerning how much of a certain type of material can be extracted and separated out from a landfill.

As explained above, the approach is set up with ten types of deposited materials, e.g. soil, paper and organic waste. In cooperation with the expert panel, mass balances for each of these material types were compiled, describing the distribution, in percentages, of each of these materials between the different separated material categories, e.g. fines, combustibles and non-ferrous, Table 2.

Table 2. Illustration of how the mass balances between the deposited material types and the separated material categories have been calculated.

\begin{tabular}{|c|c|c|c|c|c|c|c|c|c|}
\hline \multirow{2}{*}{ Material type } & \multicolumn{8}{|c|}{ Separated material category } & \\
\hline & Cat.1 & Cat.2 & Cat.3 & Cat.4 & Cat.5 & Cat.6 & Cat.7 & Cat.8 & \\
\hline Soil & $\begin{array}{l}\text { a1 } \\
(\%)\end{array}$ & $\begin{array}{l}\text { a2 } \\
(\%)\end{array}$ & $\begin{array}{l}\text { a3 } \\
(\%)\end{array}$ & $\begin{array}{l}\text { a4 } \\
(\%)\end{array}$ & $\begin{array}{l}\text { a5 } \\
(\%)\end{array}$ & $\begin{array}{l}a 6 \\
(\%)\end{array}$ & $\begin{array}{l}\text { a7 } \\
(\%)\end{array}$ & $\begin{array}{l}\text { a8 } \\
(\%)\end{array}$ & $\sum_{i=1}^{8} a_{i}=100 \%$ \\
\hline Paper & $\begin{array}{l}\text { b1 } \\
(\%)\end{array}$ & $\begin{array}{l}\text { b2 } \\
(\%)\end{array}$ & $\begin{array}{l}\text { b3 } \\
(\%)\end{array}$ & $\begin{array}{l}\text { b4 } \\
(\%)\end{array}$ & $\begin{array}{l}\text { b5 } \\
(\%)\end{array}$ & $\begin{array}{l}\mathrm{b} 6 \\
(\%)\end{array}$ & $\begin{array}{l}\text { b7 } \\
(\%)\end{array}$ & $\begin{array}{l}\text { b8 } \\
(\%)\end{array}$ & $\sum_{i=1}^{8} b_{i}=100 \%$ \\
\hline Plastic & & & & & & & & & \\
\hline Wood & & & & & & & & & \\
\hline Textiles & & & & & & & & & \\
\hline Inert materials & & & & & & & & & \\
\hline Organic waste & & & & & & & & & \\
\hline Ferrous metals & & & & & & & & & \\
\hline Non-Fe metals & & & & & & & & & \\
\hline
\end{tabular}


The efficiency of resource recovery depends to a large degree on which type of separation process is used in each scenario. Similar to the other parameters in the approach, separation efficiencies can be altered when, for instance, a landfill mining practitioner has made its own pilot studies regarding the efficiency of the technology intended to be used.

The separated material categories are modeled to be either incinerated with energy recovery, material recycled or re-deposited back into the landfill. Since the hypothetical case was based in Sweden, which has a large number of district heating plants compared to many other countries, it was assumed that separated combustible materials would be incinerated in a combined heat and power plant, with a typical ratio between produced heat and electricity of 9:1 (The Swedish Waste Association, 2010). This ratio could of course be changed, depending on the local conditions where the landfill is situated. Ranges for gross calorific values for each material, retrieved from the LCA database, were used to estimate the total amount of electricity and heat that could be generated from the combustible materials in the landfills.

\subsection{Net emissions}

Every process uses resources, which in turn produces emissions. In order to calculate the environmental pressures for the resource use for the different processes, emission factors derived from the Ecoinvent databases were used (Frischknecht \& Rebitzer, 2005). Each emission factor is accompanied with a standard deviation and an uncertainty distribution. The emissions from incineration of the combustible material were calculated based on data from Ecoinvent, but adjusted to apply to the landfilled materials' slightly higher moisture content (cf. Doka, 2007; Cossu et al., 1995; Nimmermark et al., 1998). Methane emissions from re-deposited organic matter are calculated by attaining carbon content and material composition rates from the Ecoinvent database on landfills (cf. Doka, 2007).

To calculate the net emissions, an avoided burden approach has been used (ISO, 2006b). The concept of avoided burdens can be described as the environmental impacts associated with, for instance, the virgin production of materials which are avoided when substituted by the introduction of new recyclable materials. If these avoided impacts outweigh the impacts of the recycling process, avoided burdens result. When calculating the net emissions from incineration, the current energy system is used as a baseline and the emissions from incineration of the separated combustible material category are compared to this baseline. If the latter case contributes fewer amounts of emissions than the baseline energy system, the result is avoided emissions; if not, the result is emissions.

The net emissions from incineration and recycling processes are calculated through the variation of energy system for these processes. For the hypothetical case, the energy system is set by default to Swedish mix but can be altered to, for instance, Swedish marginal or any other energy system that best describes the specific case. The emission factor from the energy system can easily be changed, depending on where the landfill is situated and what type of waste is normally used in the local waste incineration plant. To calculate the net emissions relating to leakage of landfill gas, the leakage that would otherwise occur is compared to when the landfill gas collection system is put in place through the remediation process. 


\subsection{Life-cycle impact assessment}

In total, the approach consists of more than 300 input parameters, all with a mean value, a standard deviation and an uncertainty distribution. Each parameter belongs to a certain process, and the environmental pressure for each process is calculated by multiplying three parameters from the different sections (Figure 3): the amount of material that passes through a certain process (based on material composition of landfill and efficiency of material and energy recovery), the resource use for processing that amount of material (based on resource use of processes) and finally the emission factor for the resource use (based on net emissions) which can be both positive (added emissions) or negative (avoided emissions). For the hypothetical case, four environmental impact factors were chosen to present the environmental assessment for each scenario:

- Global warming potential ( $\mathrm{CO}_{2}$-equivalent emissions)

- Acidification ( $\mathrm{SO}_{2}$-equivalent emissions)

- Eutrophication ( $\mathrm{PO}_{4}$-equivalent emissions)

- Photochemical oxidation $\left(\mathrm{C}_{2} \mathrm{H}_{4}\right.$-equivalent emissions)

During the development of the approach, the characterization factors used have been imported from a life-cycle impact assessment method based on the environmental product declarations program (IEC, 2008). These four environmental impact factors should only be seen as examples of the type of result that can be produced, and not as an indication of relevant emissions for landfill mining. It is entirely possible to replace these factors with other characterization and/or environmental impact factors according to the user's preference.

The results are based on a Monte Carlo Simulation with 50,000 runs, i.e., the simulation was run 50,000 times and for each run, new random samples for all input parameters were generated. While working with the model, the authors came to realize that the model's rate of convergence is quite fast, even with more than 300 parameters, and the result charts acquire largely the same form after only a few hundred runs. The reason for the large number of runs in the simulation is to account for extreme values and to produce smoother result charts.

When the simulation was finished, all of these samples were aggregated and presented as cumulative probability distribution charts, one chart for each environmental impact factor. The four chosen impact factors should be considered examples and can be removed or replaced with other environmental impact factors, depending on which environmental problems a user wishes to focus on. Due to the structure of the approach, it is also easy to produce results that illustrate the environmental impact of different parameters for each impact factor, and to evaluate which of all these parameters contribute the most to the results.

\section{Demonstrating the usefulness of the developed approach}

Generally, an LCA study concludes by giving the reader one final result for each of the studied environmental impact factors. To account for all the uncertainties in the study, a sensitivity analysis on the final result might be provided. This approach produces a result that is simple to understand and interpret, which for some might be considered preferable compared to a more complex result. The model described in this article, however, does not provide the recipient with a single, simplified 
answer; instead, the results consist of cumulative probability distributions for each environmental factor for each scenario.

\subsection{Scenario results}

The results from applying the approach shows the accumulated net emissions of the scenarios from each simulation run, which corresponds to the probability distribution (Figure 4). The x-axis of the result charts describes the net emissions, which can be either positive (added emissions) or negative (avoided emissions). If the entire range of possible outcomes, i.e., the curve, is located to the left of the $y$-axis, the scenario only produces results with negative net emissions, and vice versa. When scenarios have a result curve that lies on both sides of the $y$-axis, the point where the curve crosses the $y$-axis determines the probability of negative net emissions. The most probable result, the expected value, is also shown on the result charts. This expected, or mean, value can be thought of as the "final result" in standard LCA studies. Therefore, the model produces all the information that the simplified version of LCA results can give, and more.

The following example demonstrates the potential advantages of the approach: A consequential LCA consists of two possible scenarios, A and B. Results from the LCA show that the expected value for scenario $A$ is 20 percent better than the expected value for scenario $B$. In a simple approach, this might be all the information that is provided, which means that scenario $A$ is the most likely option to be selected. What this approach does not show, however, is the probabilities for these results, and the range of the different possible outcomes. When using the approach described in this article, the same expected values are attained, but the probability distribution might show that the possibility for a positive outcome for scenario A is 50 percent, while scenario $B$ has close to a 100 percent positive outcome. This addition to the results might make a landfill mining practitioner change his mind and choose scenario $B$. 


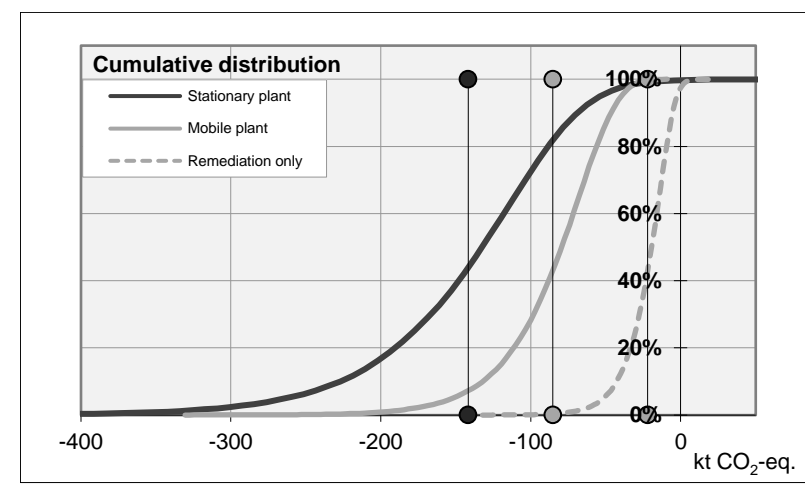

(a)

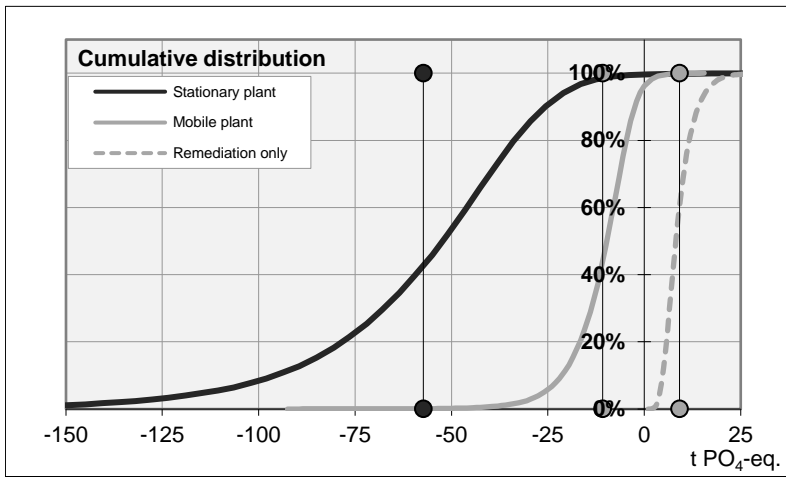

(c)

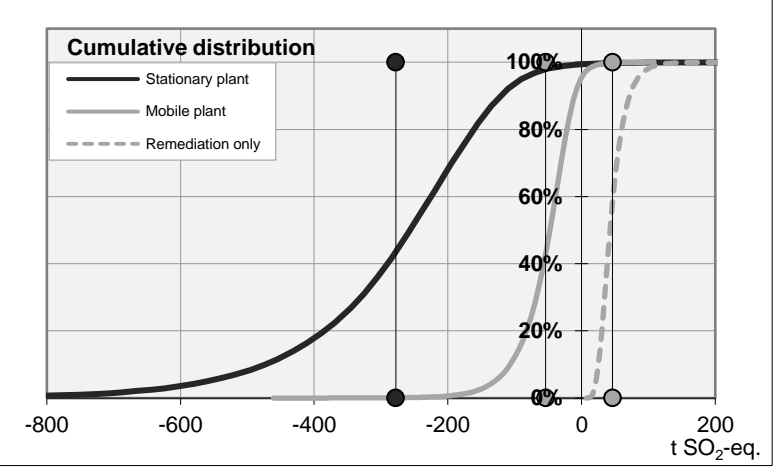

(b)

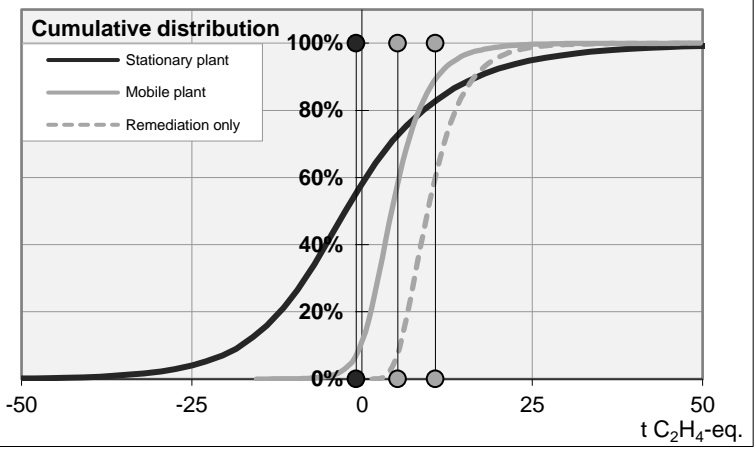

(d)

Figure 4. The four charts show the cumulative probability distribution for each scenario and environmental impact factor in the hypothetical case, based on a 50,000-sample Monte Carlo Simulation. (a) shows the amount of kilo tonnes of $\mathrm{CO}_{2}-$ equivalents (GWP 100 ), (b) shows the amount of tonnes of $\mathrm{SO}_{2}$-equivalents, (c) shows amount of tonnes of $\mathrm{PO}_{4^{-}}$ equivalents and (d) shows amount of tonnes of $\mathrm{C}_{2} \mathrm{H}_{4}$-equivalents. The vertical line illustrates the mean value for each scenario.

One general conclusion from applying the approach on the hypothetical case is that the net emissions for each environmental impact category are most likely lower in the stationary plant scenario compared to the other two scenarios, and that this scenario shows negative (avoided) emissions as the most probable outcome for all four environmental impact factors (Figure 4). However, the relative positions of the mean values between the three scenarios differ, and the appearance of the curves between the environmental impact factors is different. For instance, it appears that the biggest differences between the stationary plant and the mobile plant scenario are $\mathrm{SO}_{2}$-equivalent (acidifying) and $\mathrm{PO}_{4}$-equivalent (eutrophying) emissions, whereas for $\mathrm{CO}_{2}$-equivalent (greenhouse gas) and $\mathrm{C}_{2} \mathrm{H}_{4}$-equivalent (photochemical oxidation) emissions the differences are lower. If the former pair of environmental impacts are considered to be the most important for a landfill mining practitioner, it is imperative to maximize the possible amount of resources recovered, which is preferably done by using a large stationary plant with state-of-the-art separation facilities.

By presenting the results in this way, the project owner in the hypothetical case will get a more complete picture of the significance of the results. These results show, for instance, that the variation of possible outcomes is larger by using a stationary plant compared to using a mobile plant or to only remediate the landfill, i.e., the uncertainty concerning the specific outcome is higher. However, the uncertainty regarding whether the landfill mining project will deliver a positive or a negative environmental result is much lower in the stationary plant scenario, since a very large part of the corresponding curve is in "avoided emissions territory." 


\subsection{Large impact parameters}

An important advantage with this approach is the learning process that inevitably takes place when working with it. The complexity itself might be an enhancing factor in our understanding of the studied processes and could be considered more helpful, for instance, in deciding what actions that need to be taken for improvement. In other words, for a landfill mining practitioner, it is useful to obtain an even deeper understanding of the results than what the result charts for the scenarios and the environmental impact factors show. When planning a project intended to be as environmentally beneficial as possible, it is necessary to see which processes have large positive environmental impacts and which processes have minor or negative impacts. Additionally, it can be important for a landfill mining practitioner to understand which processes most strongly relate to each environmental impact factor, since some factors might be considered more important than others. Such knowledge will help the landfill mining practitioner in making sensible decisions about e.g. which actors/companies to involve in the project, what separation technologies and recycling options should be selected and what materials should be focused on when it comes to recycling and treatment.

Thus, in order to get a better understanding of the results for the stationary plant scenario in the hypothetical case, the parameters that have the largest impact on the results were analyzed, Figure 5.

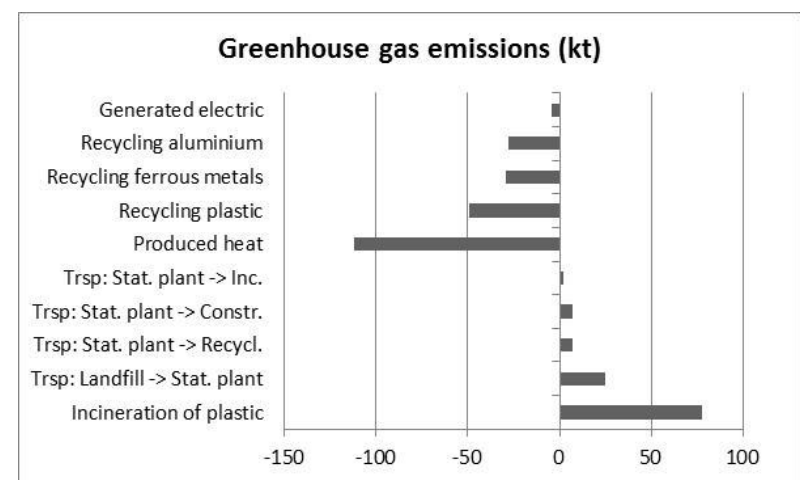

(a)

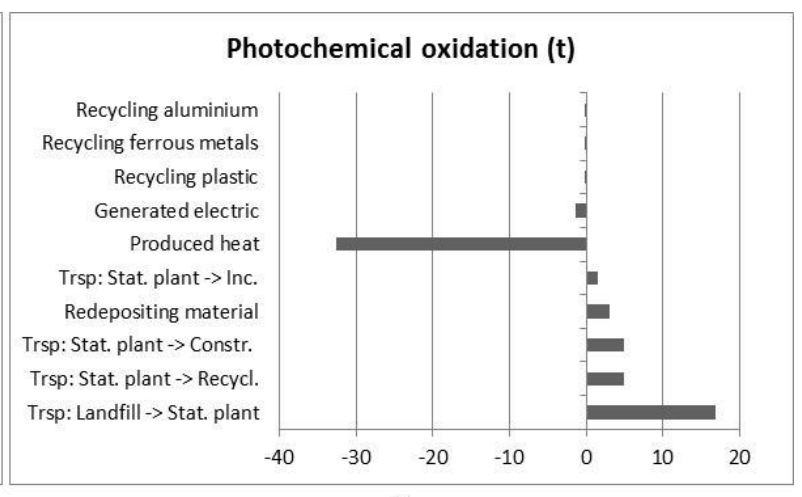

(b)

Figure 5. Large impact parameters for $\mathrm{CO}_{2}$-equivalent $\left(\mathrm{GWP}_{100}\right)(\mathrm{a})$ and $\mathrm{C}_{2} \mathrm{H}_{4}$-equivalent (b) emissions for the stationary plant scenario in the hypothetical case. Trsp = Transport, Stat. plant = Stationary plant, Inc. = Incineration plant, Constr. = Construction material site, Recycl. = Recycling facility.

From these results it is evident that the avoided greenhouse gas emissions and photochemical oxidation can largely be attributed to the amount of heat produced from incinerating the combustible (biogenic) materials. Incineration of the (non-biogenic) plastics material, however, results in a large amount of added greenhouse gas emissions. This means that it is critical for the landfill mining owner in our hypothetical case to develop business agreements with local incinerators to assure that there is a demand for the extracted combustible materials. At the moment, there seems to exist an overcapacity of incineration plants in Sweden and many incineration plants are actively searching for alternative sources for waste fuel, which of course is beneficial for a landfill mining practitioner.

A significant part of the avoided greenhouse gas emissions can also be attributed to material recycling, which means that the occurrence of plastics and metals in the landfill, combined with the 
efficiency of the separation facilities, is an important factor for our hypothetical landfill owner to consider. If, for instance, the landfill contains a larger amount of recyclable metals, the net greenhouse gas emissions of the landfill mining initiative will decrease accordingly. Another example that would significantly improve the net result of the landfill mining initiative is if a higher percentage of the plastic material in the landfill can be separated out and recycled instead of incinerated. Incinerated plastics produce added greenhouse gas emissions while recycled plastics lead to avoided greenhouse gas emissions, so the effect is twofold: less added emissions and more avoided emissions. Thus, a thorough survey concentrating on finding the best separation technologies for plastics might be a worthwhile investment for the landfill mining owner in our hypothetical case.

Transports between the landfill and the stationary plant constitute a large portion of the negative environmental effect, especially for photochemical oxidation $\left(\mathrm{C}_{2} \mathrm{H}_{4}\right)$, even though the environmental advantages from a higher recycling efficiency seem to outweigh this effect. However, the transport distances between the different facilities might still be an important factor to consider. If this factor can be decreased by using a recycling facility closer to the landfill or including more separation processes directly at the landfill site, the emissions of $\mathrm{C}_{2} \mathrm{H}_{4}$ will decrease as well.

\subsubsection{Material composition}

The material composition in the hypothetical case was based on data from material samples extracted from six locations at the landfill. This method, however, has several inherent uncertainties since the sampled material only constitutes a tiny fraction of the total deposited volume, and hence there is an obvious risk of either over- or underestimating the occurrence of a specific type of material. What if these samples contained much less of a certain material than the landfill as a whole? With the approach it is easy to answer questions like these by analyzing the uncertainty and its consequences. How would the results from the mobile plant and the stationary plant scenarios differ if the mean value for plastic material percentages was grossly underrepresented in the samples, and the actual percentage in the landfill was four times that amount, i.e., 32.4 percent instead of 8.1 percent? Even though this probably is an unrealistic percentage for a municipal solid waste landfill in Sweden, it is interesting to see how the change affects the results. What happens is that in both scenarios the amount of avoided greenhouse gas emissions decreases, as illustrated in Figure 6, but what is more interesting is that when the amount of plastic material increases, the probability for positive net emissions for the stationary plant increases as well, from close to nonexistent to around 10 percent. The reason for this increase is that more plastic material is sent to energy recovery, which, as noted in Figure 5, leads to added greenhouse gas emissions. These new results might make for a tougher choice for a landfill mining practitioner than the previous one. 


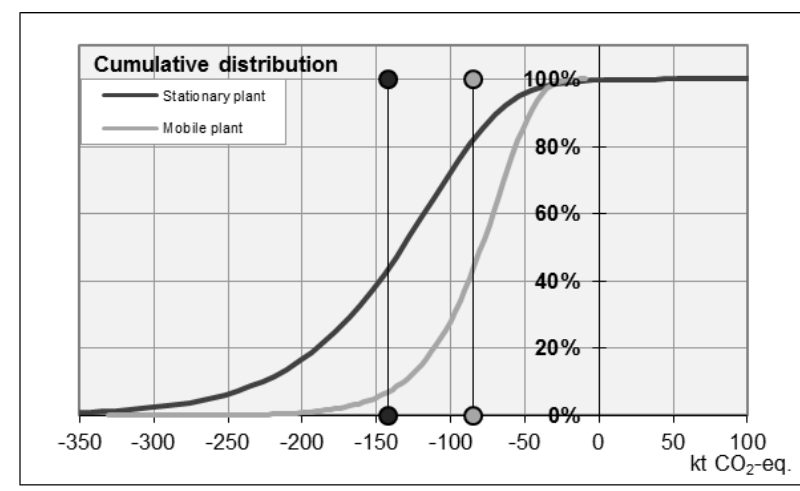

(a)

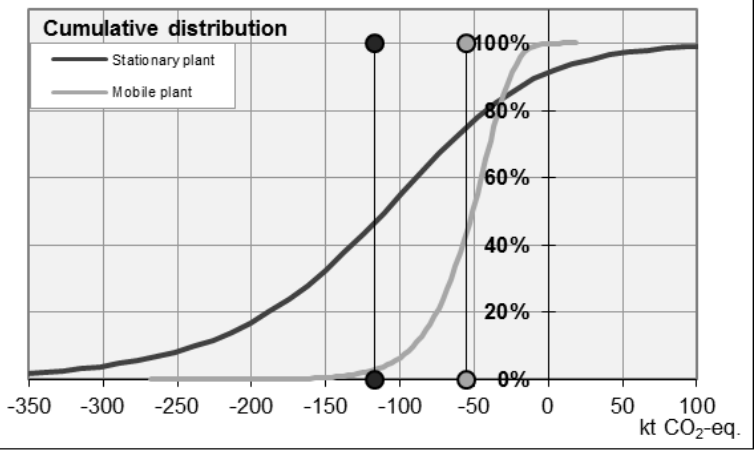

(b)

Figure 6. Cumulative probability distribution of the $\mathrm{CO}_{2}$-equivalent emissions $\left(\mathrm{GWP}_{100}\right)$ for the stationary plant and mobile plant scenarios. (a) shows the results based on a mean value of 8.1 percent of plastics in the landfill, while (b) shows the results based on a mean value of 32.4 per-cent.

\subsubsection{Transport distance}

Since transports are a large contributor to photochemical oxidation, it can be an interesting factor to further analyze. The distance between the landfill and the separation facility in the stationary plant scenario is central, so it is important for the landfill mining owner in our hypothetical case to consider how the environmental effect will change if, for instance, another separation plant located farther away from the landfill has to be used. Reasons for using another separation plant may be lack of capacity or more efficient separation processes for specific materials, e.g. plastics.

This approach makes it is possible to analyze changes like this, and to evaluate the breaking points for different parameters. At what distance between the landfill and separation facility in the stationary plant scenario does it begin to have a less favorable mean value than in the mobile plant scenario? If we change the mean value for this transport distance from the default value of $300 \mathrm{~km}$ $(+/-150 \mathrm{~km})$ to $450 \mathrm{~km}(+/-150 \mathrm{~km})$, the mobile plant scenario actually has a slightly lower mean value than the stationary plant, as shown in Figure 7. Even though the most likely outcome (the mean value) is lower photochemical oxidation for the mobile plant scenario, the possibility for negative net emissions is still higher in the stationary plant scenario, 40 percent compared to 10 percent. If the distance were $450 \mathrm{~km}$ or more between the landfill and the separation plant, a landfill mining practitioner might opt for a closer separation plant or even think about using less efficient separation technologies, such as a mobile plant. This is, of course, assuming the landfill mining practitioner considers the photochemical oxidation to be most important.

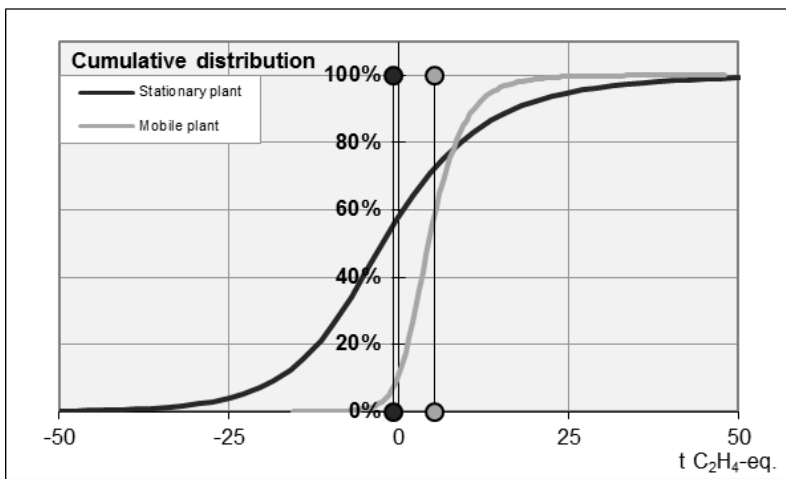

(a)

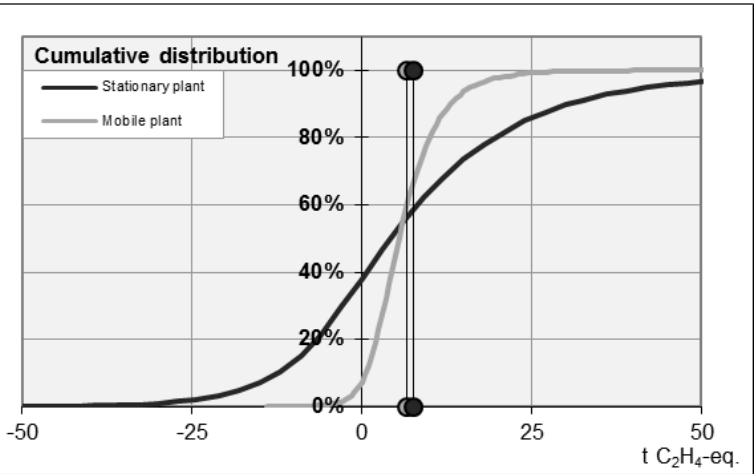

(b) 
Figure 7. Cumulative probability distribution of the $\mathrm{C}_{2} \mathrm{H}_{4}$-equivalent emissions for the stationary plant and mobile plant scenarios, when the transport distance between the landfill and the stationary plant has been changed from $300 \mathrm{~km}+/-$ 150 (a) to $450 \mathrm{~km}+/-150$ (b).

\section{Concluding discussion}

Studying complex systems such as landfill mining inherently leads to the need for simplifications and assumptions. This is also true for most environmental assessment studies, and there are different ways to handle this. A decision that has environmental consequences should preferably be based on information as holistic as possible. This implies that vast amounts of data need to be collected, interpreted and prioritized. Thus, there is a risk for what Hertwich et al. (1997) call "analytical paralysis," i.e., that the collection of data for the environmental impact evaluation is outside the limits of what can be done within the available budget or time frame. When conducting this kind of assessment, it is necessary to do simplifications without disregarding the relevance and validity of the study. A common way to make these assessments is to assign single values to each parameter in a defined model. However, this has a high probability of leading to a deterministic outcome (Lloyd and Ries, 2007). Another way to address these uncertainties is to use Monte Carlo Simulation and attach uncertainties to each parameter used in the model. In a case such as ours this is preferable, since a large number of uncertainties are present due to the lack of knowledge base from which to draw data (cf. Krook et al., 2012).

\subsection{Areas of use}

Implementation of landfill mining can be performed in several different ways. Some things are in the hands of the landfill mining practitioner, such as which recycling facilities and other actors to do business with, what kinds of separation technologies are going to be used and which material categories should be recovered. On the other hand, some parameters are largely external and not possible to change, for instance the composition of the landfill or the energy system currently in use in the region. What is similar in both these types of issues is the amount of uncertainty involved. A landfill mining practitioner will find that there is very limited access to detailed data in regards to, for instance, extraction and material separation efficiencies from landfills (Krook et al., 2012). These uncertainties can broadly be divided into two different types, "scenario uncertainties" and "parameter uncertainties" (Huijbregts et al., 2003). Scenario uncertainties comprise the uncertainties introduced with the different assumptions and choices made in order to build the different scenarios, while parameter uncertainties are related to how individual processes can vary.

Scenario uncertainties relate to which types of parameters to include in a scenario. The type of separation plant used in the scenario, the material categories that are separated, whether incineration and energy recovery is a viable option and if so, what energy system should be used in the scenario, are all scenario uncertainties relevant to a landfill mining initiative. These scenario uncertainties largely depend on the region or nation in which the landfill mining takes place, what actor is doing the landfill mining, and the aim of the landfill mining initiative. Parameter uncertainties relate to the actual value of the parameters included in the scenarios, e.g. how much of a certain material is located in the landfill, how much of this material can be separated out or the distance between the landfill and the separation facility.

The approach has a number of potential areas of use, which can be divided into five major types: evaluating strategy potential (e.g. what is the overall potential of landfill mining in a region or 
country); evaluating multiple landfill mining initiatives (e.g. which of several landfills has the best environmental potential); evaluating a landfill mining initiative with regards to scenario differences (e.g. what should be done); evaluating parameters (e.g. how should it be done); and evaluating an already finished project (e.g. what could have been done differently or how did the outcome correspond to the initial evaluation). The first area of use, to evaluate the potential of landfill mining, is primarily for use by policy makers. The policy maker might want to evaluate the environmental potential for landfill mining in a certain region or nation and take appropriate regulatory action to support this concept. Another possibility is to use this evaluation to compare landfill mining with the potential of other strategies.

If an actor interested in landfill mining has several different landfills to choose from, a broad analysis concerning the environmental potential of each landfill might be a good place to start. This can be achieved by constructing scenarios for each of the landfills. To avoid putting an unreasonable amount of work into evaluations containing a large number of landfills, a simplification of the scenarios may be necessary. This can be achieved, for instance, by combining easily accessible data on the type, age and size of each landfill, with generic data regarding material composition for these types of landfills and separation technology efficiencies. It is important to emphasize, however, that higher standard deviations should generally be used when using generic data, to account for the higher uncertainties. From this analysis the landfill mining actor should be able to conclude which landfill has the best environmental potential and do a more in-depth analysis of this particular landfill (cf. Van der Zee et al., 2004). Here the actor can choose, for instance, to evaluate different types of separation technologies and see what gives the best results. If necessary, it is also possible to evaluate specific parameters, for example, which transportation method should be used in this landfill mining initiative. After the project has been realized, an analysis can be conducted by simulating with the now-known data inserted into the model, to see how the results from this simulation relate to the initial evaluation. This last step can be a very important one, since it is a way for the landfill mining actor to learn from the experience and hence give indications about important aspects to consider in later projects.

\subsection{Further development}

This approach brings together Life Cycle Assessment, Monte Caro Simulation and landfill mining and has great potential to be important regarding landfill mining issues on many different levels. Even though the model is quite complex in its structure and contains over 330 input parameters, there is room for further improvement. A large effort will be put on validating and analyzing the model parameters and assumptions in order to further clarify, for instance, possible dependencies between different parameters and to include more data based on real cases, such as pilot studies, instead of idealized data from an LCA database.

Additionally, we will examine the inclusion of hazardous substances and how we can model their toxicological effects. This will be important since the occurrences of these substances will be the main reason for starting up the remediation effort in the first place. Since the modeling of the flows of the substances will be highly uncertain and will rely upon how the different stocks of substances are mobilized and moved between different processes, it is necessary to model both the movement of stocks and the connected flows of the substances that are found relevant. This could be done by applying a kind of initial substance flow analysis method and tracking the routes of the stocks of 
some hazardous materials through the different scenarios. When the stocks have been modeled it is then necessary to map to what extent and how the substances are emitted to the surrounding environments. After this initial analysis of the hazardous substances the assumed emissions flows can then be imported to the overall approach and treated as a new impact category, using for instance a toxicity model such as USEtox (cf. Rosenbaum et al., 2008). Remediation will most likely lead to environmental benefits in terms of less leaching from the landfill, but what is interesting to analyze is whether an increased degree of resource recovery leads to an uncontrolled spreading of hazardous substances through, for instance, unwanted co-recycling.

A final area of development, which is absolutely necessary to include if the approach is to be used for decision making, is to broaden the analysis to include economic parameters, which leads to the possibility of making a combined environmental and economic evaluation of landfill mining.

\section{Acknowledgements}

The authors gratefully acknowledge the financial support of the Swedish Research Council Formas and the technical support of Bo Persson, Xice AB and of Stena Metall AB.

\section{References}

Baas, L., Krook, J., Eklund, M., Svensson, N., 2010. Industrial ecology looks at landfills from another perspective. Regional Development Dialogue 31 (2), 169-183.

Cha, M.C., Yoon, B.H., Sung, S.Y., Yoon, S.P., Ra, I.W., 1997. Mining and remediation works at Ulsan landfill site, Korea. Proceedings Sardinia '97, Sixth International Landfill Symposium, Cagliari, Italy, 553-558.

Cobb, C.E., Ruckstuhl, K., 1988. Mining and reclaiming existing sanitary landfills. Proceedings of the National Waste Processing Conference, Detroit, MI, USA, 145-151.

Cossu, R., Motzo, G.M., Laudadio, M., 1995. Preliminary study for a landfill mining project in Sardinia. Proceedings Sardinia 95, Fifth International Landfill Symposium, Cagliari, Italy, 841-850.

Dickinson, W., 1995. Landfill mining comes of age, Solid Waste Technologies 9, 42-47.

Doka G., 2007. Life Cycle Inventories of Waste Treatment Services. Final report Ecoinvent data v2.0. Volume: 13. Swiss Centre for LCI, Empa - TSL. Dübendorf, Switzerland.

Eurostat, 2009. Waste generated and treated in Europe. Office for Official Publications of the European Communities, Luxembourg.

EPA, 1997. Landfill reclamation. EPA 530-F-97-001, United States Environmental Protection Agency.

Finnveden G., (2000) On the limitations of life cycle assessment and environmental systems analysis tools in general. International Journal of Life Cycle Assessment 5, 229-238.

Flyhammar, P., 1997. Heavy metals in municipal solid waste deposits. Lund University of Technology, Water Resources Engineering, AFR-report 231, Lund, Sweden.

Frischknecht and Gerald, R., Rebitzer, G., 2005. The ecoinvent database system: a comprehensive web-based LCA database. Journal of Cleaner Production, Volume 13, Issues 13-14, 1337-1343

Heijungs, R., Huijbregts, M.A.J., 2004. A review of approaches to treat uncertainty in LCA. p.332-339. In C. Pahl-Wostl, S. Schmidt, A.E. Rizzoli, \& A.J. Jakeman (eds). Complexity and Integrated Resources Management.Transactions of the 2nd Biennial Meeting of the International Environmental Modelling and Software Society, Volume 1. iEMSs (ISBN 88-900787-1-5), Osnabrück. 2004, 1533 pp.

Hertwich, E. G., Pease W. S., Koshland C., 1997. Evaluating the environmental impact of products and production processes: a comparison of six methods. The Science of the Total Environment 196, 13-29. 
Hino, J., Miyabayashi, Y., Nagato, T., 1998. Recovery of nonferrous metals from shredder residue by incinerating and smelting. Metallurgical Review of MMIJ (Mining and Metallurgical Institute of Japan) 15, 63-74.

Hogland, W., Jagodzinski, K., Meijer, JE., 1995. Landfill mining tests in Sweden. Proceedings Sardinia '95, Fifth International Landfill Symposium, Cagliari, Italy, 783-794.

Hogland, W., 2002. Remediation of an old landfill: soil analysis, leachate quality and gas production. Environ Science \& Pollution Research 1, 49-54.

Hogland, W., Marques, M., Nimmermark, S., 2004. Landfill mining and waste characterization: a strategy for remediation of contaminated areas. Journal of Material Cycles and Waste Management 6, 119-124.

Hong, J., Shaked, S., Rosenbaum, R. K., Jolliet, O., 2010. Analytical uncertainty propagation in life cycle inventory and impact assessment: application to an automobile front panel. Int J Life Cycle Assess 15, 499-510.

Huijbregts, M. A., Gilijamse, W., Ragas, A. M. J., Reijnders, L., 2003. Evaluating Uncertainty in Environmental Life-Cycle Assessment. A Case Study Comparing Two Insulation Options for a Dutch One-Family Dwelling. Environ. Sci. Technol., Vol. 37, No 11, pp 2600-2608.

Hull, R.M., Krogmann, U., Strom, P.F., 2005. Composition and Characteristics of Excavated Materials from a New Jersey Landfill. Journal of Environmental Engineering 131, 478-490.

IEC, 2008. The International EPD Cooperation: Introduction, intended uses and key programme elements for environmental product declarations, EPD. Available at: http://www.environdec.com ISO, 2006. International Organization of Standardization 14040: environmental management - life cycle assessment - principles and framework. SIS - Swedish Standards Institute, Stockholm.

ISO, 2006b. International Organization of Standardization 14044: environmental management - life cycle assessment - requirements and guidelines. International Organization for Standardization, Geneva, Switzerland.

Kalos, M. H., Whitlock, P. A., 2008. Monte Carlo Methods. Wiley-Interscience.

Kapur, A., Graedel, T.E., 2006. Copper mines above and below ground. Estimating the stocks of materials in ore, products, and disposal sites opens up new ways to recycle and reuse valuable resources. Environmental Science \& Technology 40, 3135-3141.

Kollikkathara, N., Feng, H., Stern, E., 2009. A purview of waste management evolution: Special emphasis on USA. Waste Management 29, 974-985.

Krogmann, U., Qu, M., 1997. Landfill mining in the United States. Proceedings Sardinia '97, Sixth International Landfill Symposium, Cagliari, 543-552.

Krook, J., Svensson, N., Eklund, M., 2012. Landfill Mining: A critical review of two decades of research. Waste Management 32, 513-520.

Kurian, J., Esakku, S., Palanivelu, K., Selvam, A., 2003. Studies on landfill mining at solid waste dumpsites in India. Proceedings Sardinia '03, Ninth International Landfill Symposium, Cagliari, Italy, 248-255.

Kurian, J., Esakku, S., Nagendran, R., 2007. Mining compost from dumpsites and bioreactor landfills. Int. J. Environmental Technology and Management 7, 317-325.

Lloyd, S. M., Ries, R., 2007. Characterizing, Propagating, and Analyzing Uncertainty in Life-Cycle Assessment - A Survey of Quantitative Approaches. Journal of Industrial Ecology, Vol. 11, No. 1, 161-179.

Metropolis, N., Ulam, S., 1949. The Monte Carlo Method. Journal of the American Statistical Association, Vol. 44, No. 247., 335-341.

Mor, S., Ravindra, K., De Visscher, A., Dahiya, R.P., Chandra, A., 2006. Municipal solid waste characterization and its assessment for potential methane generation: A case study. Science of the Total Environment 371, 1-10.

Nimmermark, S., Hogland, W., Larsson. L. and Bladh, H., 1998. Utgrävningar vid deponierna Måslycke och Gladsax Hallar i Simrishamns kommun. Rapport 107, Kalmar University College and Lund University [in Swedish]. 
Obermeier, T., Hensel, J., Saure, T., 1997. Landfill mining: energy recovery from combustible fractions. Proceedings Sardinia '97, Sixth International Landfill Symposium, Cagliari, Italy, 569578.

Quaghbeur, M., Laenen, B., Nielsen, P., Geysen, D., 2010. Valorisation of materials within enhanced landfill mining: what is feasible?. Proceedings The International Academic Symposium on Enhanced Landill Mining, Houthalen-Helchteren, Belgium, 113-128.

Reap, J., Roman, F., Duncan, S., Bras, B., 2008. A survery of unresolved problems in life cycle assessment. Int J Life Cycle Assess, Vol. 13, 374-388.

Rettenberger, G., 1995. Results from a landfill mining demonstration project. Proceedings Sardinia '95, Fifth International Landfill Symposium, Cagliari, Italy, 827-840.

Richard, D., Ambrosie, R., Zavoral, P., Zimmerman, R., 1996. Fargo takes a second look at the old landfill site. Proceedings of the 19th International Madison Waste Conference, University of Wisconsin-Madison/Extension, Madison, WI, USA.

Rosenbaum, R.K. ,Bachmann, T.M., Gold, L.S., Huijbregts, M.A.J., Jolliet, O., Juraske, R., Koehler, A., Larsen, H.F., MacLeod, M., Margni, M., McKone, T.E., Payet, J., Schuhmacher, M., Van De Meent, D., Hauschild, M.Z., 2008. USEtox - The UNEP-SETAC toxicity model: Recommended characterisation factors for human toxicity and freshwater ecotoxicity in life cycle impact assessment. Int J Life Cycle Assess, Vol. 13, 532-546.

Savage, G.M., Golueke, C.G., von Stein, E.L., 1993. Landfill mining: Past and present. Biocycle 34, 5861.

Sormunen, K., Ettala, M., Rintala, J., 2008. Detailed internal characterisation of two Finnish landfills by waste sampling. Waste Management 28, 151-163.

Spencer, R., 1990. Landfill space reuse. Biocycle 31, 30-33.

Stessel, R.I., Murphy, R.J., 1991. Processing of material mined from landfills. Proceedings of the National Waste Processing Conference, Publ. by ASME, Detroit, MI, USA, 101-111.

The Swedish Waste Association, 2010. Svensk avfallshantering 2010. Malmö, Sweden. Available at: http://www.avfallsverige.se

Van der Zee, DJ., Achterkamp, MC., de Visser, BJ., 2004. Assessing the market opportunities of landfill mining. Waste Management 24, 795-804.

Zanetti, M., Godio, A., 2006. Recovery of foundry sands and iron fractions from an industrial waste landfill. Resources, Conservation and Recycling 48, 396-411. 